\title{
Experiências de pais e mães na revelação da orientação não heterossexual de filhos/as
}

\author{
Monalisa Col Debella \\ Icaro Bonamigo Gaspodini
}

\begin{abstract}
RESUMO
A revelação da orientação não heterossexual (coming out) de um indivíduo para a família pode ser um processo complexo, por vezes longo e conflituoso. Esta pesquisa teve como objetivo investigar como pais e mães que residiam em uma cidade do interior da mesorregião noroeste rio-grandense, experienciaram a revelação da orientação não heterossexual de filhos/as. Trata-se de um estudo qualitativo, de cunho exploratório e descritivo. Participaram seis mães e pais de pessoas que haviam revelado sua orientação não heterossexual para a família. Foram realizadas entrevistas semiestruturadas, as quais foram gravadas em áudio, transcritas na íntegra e posteriormente submetidas à análise temática. Os resultados mostraram duas formas de aceitação, a imediata e a conturbada, além de elementos comuns às duas formas. A aceitação imediata foi potencializada pela percepção prévia da homossexualidade do/a filho/a e por informações sobre diversidade sexual e de gênero. A aceitação conturbada foi motivada por fatores como a esperança de que o/a filho/a mudasse ou culpa pela orientação sexual do/a filho/a. Entre os elementos comuns, destaca-se o medo do preconceito e a reavaliação de expectativas sobre o/a filho/a.
\end{abstract}

Palavras-chave: família; relação familiar; orientação sexual; homossexualidade; bissexualidade.

\section{ABSTRACT}

\section{Parent-mother experiences in revelation of non-heterosexual orientation of children}

Coming out as non-heterosexual for the family may be a complex process, sometimes long and conflictive. This research aimed to investigate how parents experience the revelation of non-heterosexual orientation of children in a countryside city in the southernmost state of Brazil. This is a qualitative, exploratory and descriptive study. Six parents of individuals who had previously revealed their non-heterosexuality participated in this research. Semi-structured interviews were recorded, transcribed, and later submitted to thematic analysis. Results showed two forms of acceptance: immediate and troubled, with elements in common. Immediate acceptance was related to the prior perception of the child's homosexuality and information on diversity issues. Troubled acceptance was motivated by expecting that the child became heterossexual and blame for the children's sexual orientation. Common elements were mainly the fear of prejudice and reassessment of expectations towards their children.

Keywords: family; family relationship; sexual orientation; homosexuality; bisexuality.

Na maior parte das sociedades, ainda se considera que a heterossexualidade seja a orientação sexual natural e culturalmente esperada. Consequentemente, orientações sexuais não heterossexuais são vistas como diferentes, inferiores e anormais (Murasaki \& Galheigo, 2016). As definições de normalidade e anormalidade em relação à orientação sexual fazem parte de uma construção social (Weeks, 2018). As crenças, identidades e comportamentos sexuais não são o

\section{Sobre os autores}

M. C. D.

https://orcid.org/0000-00017386-0261

Faculdade Meridional - Passo Fundo, RS

monalisa.coldebella@hotmail.com

I. B. G.

https://orcid.org/0000-0003-

4177-4734

Faculdade Meridional - Passo

Fundo, RS

icaro.gaspodini@imed.edu.br

\section{Direitos Autorais}

Este é um artigo de acesso aberto e pode ser reproduzido livremente, distribuído, transmitido ou modificado, por qualquer pessoa desde que usado sem fins comerciais. 0 trabalho é disponibilizado sob a licença Creative Commons CC-BY-NC.

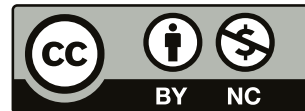




\section{M." INTERACÃO EM PSICOLOGIA}

resultado de uma simples evolução natural, pois têm sido modelados no interior de relações de poder e de dominação.

Frequentemente, confunde-se a orientação sexual para quem o indivíduo orienta seu desejo - com a identidade ou expressão de gênero - como o indivíduo se sente e se expressa em relação a categorias de masculinidade ou feminilidade (Jesus, 2013; Sennott \& Smith, 2011). Enquanto o gênero representa o sentimento de pertencimento ao masculino ou feminino, a orientação sexual se refere a um padrão de atrações sexuais, físicas, afetivas ou românticas direcionada para homens, mulheres, ambos, nenhum, ou por pessoas não binárias, ou seja, aquelas que não se identificam com um gênero específico (American Psychological Association - APA, 2017). Orientações sexuais e identidades ou expressões de gênero não podem ser consideradas patologias ou desvios de comportamento, pois são manifestações da diversidade humana (APA, 2011).

Os termos "heterossexual" e "homossexual" foram originalmente utilizados por Karl Maria Kertbeny, em 1869, buscando colocar na pauta política da Alemanha a questão da reforma sexual e a revogação das leis anti-sodomitas (Weeks, 2018). No entanto, posteriormente, no final do século $\mathrm{XIX}$, esses termos formam utilizados por sexólogos para uma descrição médico-moral que buscavam a definição dos tipos e formas do comportamento e das identidades sexuais. Uma parte importante desse processo centrava-se na definição do que constitui a anormalidade. Esses esforços de definição foram elementos importantes na institucionalização da heterossexualidade como o normal e a homossexualidade como o anormal.

No Brasil, ao final do século XX, a crise do capitalismo e o aumento dos credos religiosos institucionalizados geraram um bom espaço para as aversões morais (Trevisan, 2000). Atualmente, o mesmo processo volta à cena, com personagens políticos diferentes, mas com estratégias semelhantes em que os grupos anteriormente citados são alvos fáceis, como o movimento feminista ou o movimento LGBT (lésbicas, gays, bissexuais, transexuais, travestis e outras identidades). Desde aquela época, novas doutrinas supostamente contrárias à "decadência moral" vêm sendo utilizadas majoritariamente por bancadas compostas por fundamentalistas religiosos, ruralistas e armamentistas. A crença de que a heterossexualidade é natural e superior às outras orientações (Gato et al., 2011; Jesus, 2013) atua no processo de estigmatização, inferiorização e desumanização das minorias sexuais, o que pode culminar em violência física e verbal (Cazelatto \& Cardin, 2016).

Diante do preconceito social sofrido por pessoas não heterossexuais, a família constitui uma importante rede de apoio. Há muitos fatores que influenciam na forma como pais e mães passarão pelo processo de revelação da orientação não heterossexual de seus filhos e filhas. Esse processo é conhecido como "revelação", ou "coming out", e se refere ao meio pelo qual se aceita e reconhece a própria orientação, além da forma pela qual a orientação é revelada para os outros (APA, 2012). Assim, o coming out apresenta um componente pessoal, individual e social (Frazão \& Rosário, 2008). Nesse sentido, a família é percebida como o principal alicerce para que o indivíduo possa revelar sua orientação sexual diante de si e da sociedade (Zimmerman et al., 2015). No entanto, as reações da família diante da revelação da não heterossexualidade dependerá de atributos do desenvolvimento individual e atributos específicos da família, pares, escola, vizinhança, trabalho, relações sociais, comunidade LGBT, geração, dentre outras.

Em uma abrangente revisão da literatura internacional, foram reunidos estudos para entender as reações do pais na revelação da orientação sexual de filhos gays, lésbicas e bissexuais (Chrisler, 2017). Constatou-se que os pais podem oferecer resposta positiva, negativa ou combinada na revelação de seus filhos, podendo se envolver em técnicas ativas ou evitativas para lidar com a nova informação. Ao examinar a reações dos pais para o desenvolvimento da identidade de seus filhos após o coming out, descobriu-se que o apoio dos pais à orientação sexual do filho, as tentativas dos pais de mudar a orientação sexual do filho e as lutas dos pais em aceitar a orientação sexual têm implicações distintas no desenvolvimento da identidade dos jovens e no ajuste psicológico (D'Amico et al., 2015).

Ao examinar as reações dos pais frente a jovens britânicos do sul da Ásia que se identificam como gays, observou-se que os pais também podem precisar de apoio para aceitar a identidade sexual de seus filhos de uma maneira que seja social e psicologicamente benéfica para ambos (Jaspel, 2019). As respostas dos pais à orientação sexual de um filho/a são críticas para moldar a saúde de adolescentes lésbicas, gays e bissexuais (Huebner et al., 2019). O apoio dos membros da família tem grande impacto no desenvolvimento saudável da identificação sexual de pessoas não heterossexuais (Brandon-Friedman \& Kim, 2016).

Frente ao exposto, considera-se que entender como pais e mães experienciam esse processo se torna importante, já que a revelação da não heterossexualidade para a família abrange movimentos que ainda não são inteiramente compreendidos (Ferreira, 2012). Como esse processo pode ser mais fácil ou difícil dependendo do contexto, pensa-se que regiões de interior apresentem peculiaridades que precisam ser conhecidas. Este estudo teve como objetivo investigar como pais e mães que residem em uma cidade do interior da mesorregião noroeste rio-grandense, experienciam a revelação da orientação não heterossexual de filhos/as. 


\section{WH MTERAC̄̄OEM itu PSICOLOGIA}

\section{MÉTODO}

\section{DELINEAMENTO}

Trata-se de um estudo qualitativo, de cunho exploratório e descritivo.

\section{PARTICIPANTES}

Participaram da pesquisa seis pessoas com idade entre 39 e 58 anos. Para ser incluso na pesquisa, era preciso ser pai ou mãe de indivíduo que já tivesse revelado sua orientação não heterossexual. Optou-se por não incluir na pesquisa pais e mães de pessoas não heterossexuais que também fossem transexuais. Isso porque a revelação da transexualidade, além da revelação da não heterossexualidade, apresentaria dinâmicas interseccionais diferentes do objetivo do estudo. Além disso, não participaram da pesquisa pais ou mães de filhos/as falecidos. Inicialmente, optou-se por utilizar o critério de saturação para seleção de participantes, no qual entrevista-se tantos indivíduos quanto necessários até que os dados comecem a se repetir (Fontanella et al., 2011). No entanto, as dificuldades de acesso a participantes potencialmente dispostos a conversar sobre o tema, especialmente na região estudada, levaram à opção pelo maior número possível de entrevistas. Onze pessoas foram contatadas ao todo, no entanto, somente seis dispuseram-se a participar do estudo. Todos os participantes residiam em uma cidade da mesorregião noroeste rio-grandense, de descendência majoritariamente italiana e com população aproximada de 40 mil habitantes. Na Tabela 1, são apresentadas as principais características dos participantes.

\section{INSTRUMENTOS}

Um questionário sociodemográfico foi construído com o objetivo de coletar dados tais como idade, gênero, orientação sexual do familiar e seu filho/a, estado civil, religião, renda familiar, escolaridade e profissão. Além disso, foi construído um roteiro de entrevista semiestruturada, no qual buscou-se compreender a experiência de pais ou mães quanto à revelação da orientação não heterossexual de filhos/as. As entrevistas semiestruturadas utilizam perguntas fechadas e abertas, as quais possibilitam discorrer sobre o tema sugerido, seguindo um roteiro de perguntas previamente definidas, podendo adicionar outras de acordo com a necessidade do pesquisador (Boni \& Quaresma, 2005).

\section{PROCEDIMENTOS ÉTICOS E DE COLETA DE DADOS}

Esta pesquisa foi aprovada pelo Comitê de Ética em Pesquisa (CEP) da Faculdade Meridional IMED e foi aprovado mediante parecer número 2.225.925 (CAAE 73086017.8.0000.5319). Os procedimentos estão de acordo com as Resoluções $n^{\circ}$ $466 / 2012$ e 510/2016, as quais estabelecem diretrizes e normas regulamentadoras de pesquisas envolvendo seres humanos.

Mediante aprovação do CEP, foi realizado o primeiro contato com os participantes, via telefone e por meio de redes sociais. As entrevistas foram agendadas de acordo com horários e locais disponíveis. Todos os participantes optaram por realizar as entrevistas em suas próprias residências, por ser o ambiente onde se sentiriam mais confortáveis. Os participantes foram informados quanto aos objetivos e métodos da pesquisa, riscos e benefícios, confidencialidade e sigilo, possibilidade de desistência a qualquer momento, além da devolução e comunicação dos resultados. Posterior à explicação dos tópicos, os participantes registraram sua aprovação mediante assinatura do Termo de Consentimento Livre e Esclarecido.

Tabela 1. Descrição dos Participantes

\begin{tabular}{cccccccccc}
\hline $\begin{array}{c}\text { Mãe ou } \\
\text { Pai }\end{array}$ & Gênero & $\begin{array}{c}\text { Gênero do } \\
\text { filho/a }\end{array}$ & O. S. & $\begin{array}{c}\text { O. S. } \\
\text { filho/a }\end{array}$ & Idade & $\begin{array}{c}\text { Idade } \\
\text { filho/a }\end{array}$ & $\begin{array}{c}\text { Idade filho na } \\
\text { revelação }\end{array}$ & Escolaridade & Estado civil \\
\hline M1 & F & F & Hétero & Homo & 47 & 25 & 15 & S. I. & Casada \\
M2 & F & M & Hétero & Bi & 58 & 17 & 16 & S. C. & Solteira \\
M3 & F & M & Hétero & Homo & 39 & 20 & 18 & F. C. & Viúva \\
M4* & M & F & Hétero & Homo & 40 & 18 & 16 & S. I. & Solteiro \\
M5 & F & M & Hétero & Homo & 44 & 26 & 26 & M. C. & Casada \\
P1 & M & M & Hétero & Homo & 53 & 29 & 17 & F. C. & Viúvo \\
\hline
\end{tabular}

Nota. *O participante M4 se declara como um homem transexual, embora refira-se a si mesmo como mãe. 0 . $\mathrm{S}$. = Orientação sexual. Hétero $=$ heterossexual. Homo $=$ homossexual. $\mathrm{Bi}=$ bissexual. $\mathrm{S}=$ Ensino Superior. $\mathrm{F}=$ Ensino Fundamental. $\mathrm{M}=$ Ensino Médio. $\mathrm{I}$ = incompleto. $\mathrm{C}$ = completo. 


\section{W NTERAC̄̃OEM ET PSICOLOGIA}

\section{ANÁLISE DOS DADOS}

As gravações em áudio/vídeo foram transcritas na íntegra e o material foi submetido à análise temática de acordo com as diretrizes propostas por Braun e Clarke (2006). A análise temática é um método qualitativo de análise amplamente utilizado na Psicologia. Permite identificar, avaliar e reportar padrões nos dados, possibilitando ainda a organização e descrição dos mesmos com riqueza de detalhes (Braun \& Clarke, 2006). Os passos seguidos neste estudo foram os seguintes: 1) familiarização com os dados; 2) criação de códigos iniciais; 3) pesquisa de temas, identificando e organizando os temas e subtemas; 4) revisão dos temas; 5) definição e nomeação dos temas, criando um mapa temático dos dados; 6) produção do relatório final.

\section{RESULTADOS E DISCUSSÃO}

A Figura 1 apresenta o mapa temático resultante da análise das transcrições. Os temas foram representados por círculos e os subtemas por retângulos. Percebeu-se que existem duas formas de aceitação: a imediata e a conturbada, cada uma com seus subtemas relacionados, sendo que ambas apresentas elementos comuns. Os temas e subtemas serão discutidos a seguir, com o auxílio de tabelas contendo excertos de texto ilustrativos.
A Tabela 2 apresenta excertos de texto relacionados aos subtemas da aceitação imediata diante da revelação de fiIhos/as. Para esses participantes, a revelação foi um processo que não gerou grande impacto emocional e a aceitação foi imediata. Não houve relato de sofrimento ou desconforto, mostrando reações positivas e de aceitação. No estudo de Robinson e Brewster (2016), observou-se que há famílias com maior facilidade de adaptação, assim, a revelação ocorre sem estresse emocional com maior possibilidade de o indivíduo não heterossexual ser acolhido.

0 ambiente familiar pode ser o âmbito em que se desestimula o preconceito e onde o sujeito pode experimentar sua identidade LGBT (Afonso, 2015). Nota-se que um dos fatores que facilitou a aceitação da M3 foi que a revelação da não heterossexualidade do filho era esperada. Savin-Williams e Dubé (1998) referem que pais que suspeitaram anteriormente da não heterossexualidade do/a filho/a podem não reagir com choque diante da revelação.

Embora M3 tenha afirmado desconhecimento sobre diversidade sexual e de gênero, considerava-se "mais liberal" e "não tão rígida" no momento em que o filho revelou sua não heterossexualidade. Por não desejar que o filho atendesse as expectativas sociais desejáveis, possivelmente enfrentou a situação com tranquilidade. Nesse sentido, Baiocco et al. (2015) afirmam que famílias que são mais engajadas

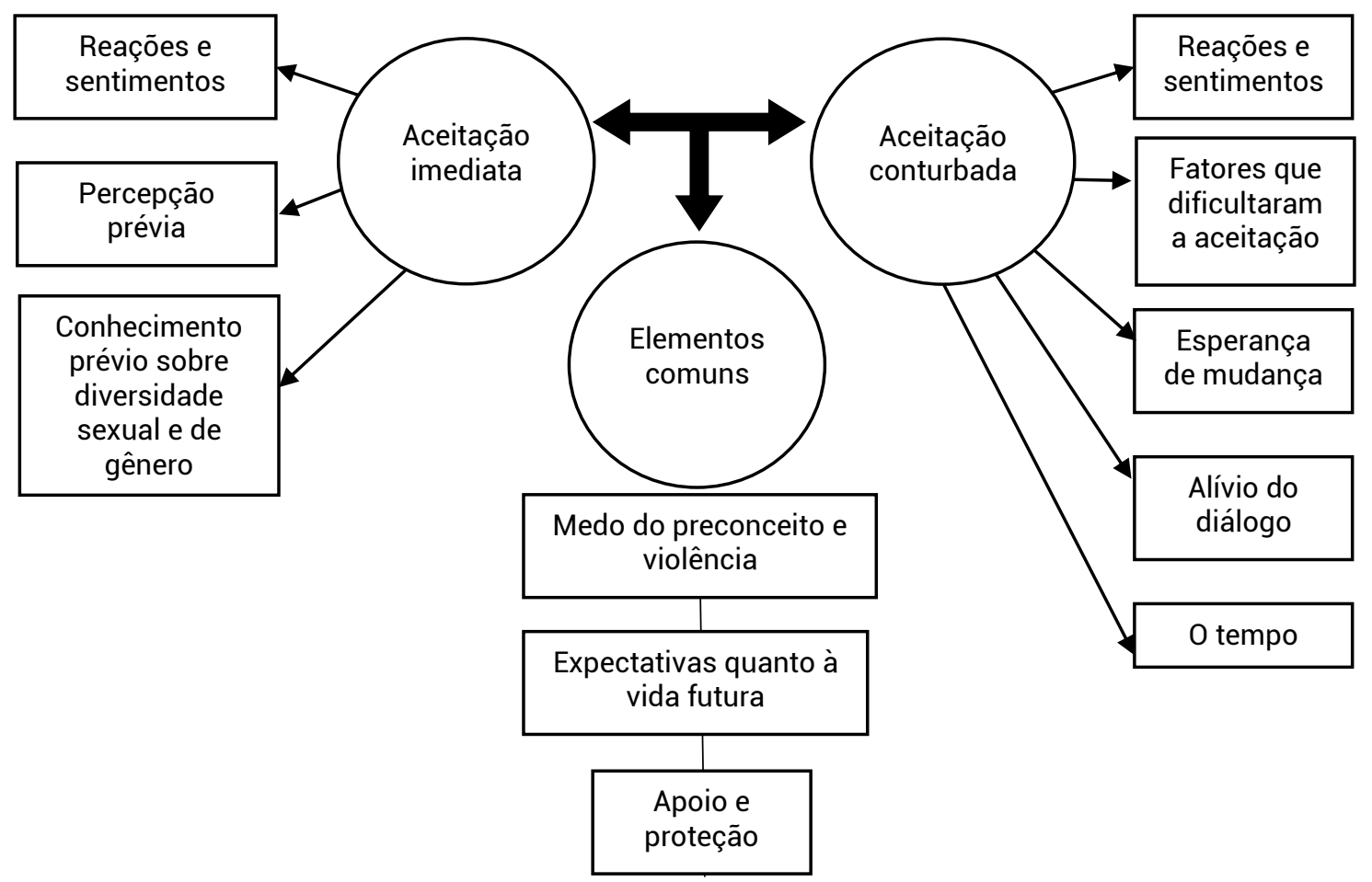

Figura 1. Mapa temático com 3 temas e 11 subtemas. 
Tabela 2. Aceitação Imediata

\begin{tabular}{|c|c|}
\hline Subtemas & Excertos \\
\hline Reações e sentimentos & $\begin{array}{l}\text { "Ele disse, 'mãe, eu sou gay', daí eu disse, 'eu já sabia'. Só precisava que ele contasse, } \\
\text { e foi assim, calmo, tranquilo" (M3). }\end{array}$ \\
\hline Percepção prévia & $\begin{array}{l}\text { "Eu vim percebendo que era diferente, então acho que isso já foi me preparando, meu } \\
\text { psicológico já estava preparado para o baque [choque]" (M3). }\end{array}$ \\
\hline $\begin{array}{l}\text { Conhecimento prévio sobre } \\
\text { diversidade sexual e de gênero }\end{array}$ & $\begin{array}{l}\text { "Eu sabia bastante coisa né, porque convivia nesse meio, então sabia quase tudo [...] } \\
\text { até com minha própria experiência" (M4). }\end{array}$ \\
\hline
\end{tabular}

em opiniões conservadoras podem ter mais dificuldade na aceitação, em razão dos paradigmas homofóbicos dos quais partem suas percepções. Na pesquisa de Cassar e Sultana (2016), observou-se que há influências culturais e religiosas que preparam o cenário para a forma como os pais irão reagir diante da revelação da homossexualidade de um filho/a.

No interessante caso de M4, a aceitação da homossexualidade de sua filha ocorreu de forma tranquila pelo fato de M4 ser um homem transexual. Por ele já ter experienciado as dificuldades de revelar sua transexualidade, encarou a revelação da não heterossexualidade da filha como natural. No entanto, a filha, por sua vez, não aceita com tranquilidade a identidade de gênero de M4, ainda o tratando por "mãe". M4 relata que a filha diz: "Ah, eu queria uma mãe normal". Segundo D'Augelli (2005), as reações da família diante da revelação da não heterossexualidade dependerão de atributos do desenvolvimento individual, bem como de específicos da família. Sabe-se, ainda, que quando os pais possuem amigos ou familiares homossexuais, o ajuste parental se torna mais acessível (Oswald, 2002). No entanto, a aceitação de pais para filhos pode diferir da aceitação de filhos para pais, o que foi observado em relação à filha de M4. Embora M4 declare seu gênero como masculino, ainda se declara e nomeia-se como "mãe", possivelmente devido à dificuldade de aceitação da filha.

$\mathrm{Na}$ Tabela 3, foram apresentados excertos de texto relacionados à aceitação conturbada diante da revelação da orientação não heterossexual de filhos/as. Foram analisadas as falas de M1, M2, M5 e P1. Para esses participantes, o processo de revelação foi mais complexo e conturbado. Os sentimentos relatados em relação à revelação são de tristeza, medo, culpa, vergonha e nervosismo. As reações são de choque, desespero, choro, sensação de estar "anestesiado", sensação de "o mundo estar desabando", "ficar sem chão" e "não saber como lidar com a situação".

A família é um dos espaços mais importantes no qual a gestão da homossexualidade pode aparecer como problema central (Saggese 2009). No processo de revelação da não he- terossexualidade de um filho para a família, existem reações parentais que são comuns na maioria dos casos, como negação, medo e aceitação (Ferreira, 2012). Em uma pesquisa realizada por Saltzburg (2007), houve um consenso entre os pais sobre se sentir atordoado e a sensação de catástrofe diante da revelação da não heterossexualidade de um filho, o que contribuiu para um estado de crise. Na revisão integrativa de literatura cientifica realizado por Nascimento e Scorsolini-Comin (2018), a respeito da revelação da homossexualidade a família, observou que muitos estudos apontam que o processo de revelação de um filho/a pode gerar diversas formas de violência no âmbito familiar, além de situações de tensão, ocasionando sofrimento psíquico.

Pode-se perceber que o sentimento de culpa de M2 pela orientação sexual do filho a fez questionar sobre possíveis erros na educação, atribuindo à falta do pai no ambiente familiar um fator que poderia ter influenciado. Nesse sentido, Toledo e Filho (2013) afırmam que é comum que pais e mães de homossexuais experimentem sentimento de culpa, responsabilizando-se, como se tivessem 'falhado' na educação dos filhos. No estudo de Jaspal (2019), onde foram entrevistados onze pais de filho/as que relevaram sua orientação homossexual, observou que alguns pais acreditam que o filho se tornar gay é devido a uma má parentalidade levando a auto-culpa. Nota-se que a falta de conhecimento sobre o tema e os mitos muitas vezes presentes na sociedade sobre a diversidade sexual e de gênero podem causar o sofrimento e sentimento de culpa nas famílias.

Muitos fatores podem estar associados à forma como os pais passarão por esse processo, aceitando o filho com maior facilidade ou não. No caso de M1, M2, M5 e P1, percebem-se alguns fatores que podem estar associados à dificuldade inicial de aceitação, como: o próprio preconceito em relação a diversidade sexual e de gênero, a preocupação quanto ao preconceito social, a vergonha diante da sociedade, a falta de conhecimento sobre o tema, a educação/cultura e a geração/idade. 
Tabela 3. Aceitação conturbada

\begin{tabular}{|c|c|}
\hline Subtemas & Excertos \\
\hline $\begin{array}{c}\text { Reações e } \\
\text { sentimentos }\end{array}$ & $\begin{array}{l}\text { "O primeiro momento foi meio conturbado... a gente não espera, né? Senti assim, um pouco triste [...]. } \\
\text { A gente tolera, mas sempre com um pé atrás" (M1). } \\
\text { "Fiquei pensando, o que eu ia fazer, como iria agir, fiquei sem chão, desnorteada, não sei nem te dizer } \\
\text { que palavra [...] eu fiquei anestesiada [...] parecia que eu ia explodir" (M2). } \\
\text { "Pensei 'onde é que eu errei na educação dele?' [...]. Às vezes, fico me perguntando, "será que foi porque } \\
\text { ele não teve o pai presente?' [...]" (M2). } \\
\text { "A reação foi de espanto, sabe? [...] Tu sabia e não admitia, naquela hora [...] parece que o mundo tinha } \\
\text { desabado" (M5). } \\
\text { "Ah... A princípio [...] a gente fica meio... que nem uma dor, um nervosismo [...] às vezes a gente ficava } \\
\text { triste" (P1). }\end{array}$ \\
\hline $\begin{array}{l}\text { Fatores que } \\
\text { dificultaram a } \\
\text { aceitação }\end{array}$ & $\begin{array}{l}\text { "Foi difícil, até pela nossa educação mesmo [...] porque é um assunto ruim de conversar, que a gente } \\
\text { não sabe nem como chegar [...]. Era melhor ter ficado como a gente [heterossexual]" (M1). } \\
\text { "A gente se preocupa muito com os outros, mas a gente foi criada assim [...] eu nasci quase } 60 \text { anos } \\
\text { atrás. Por mais que tu estude, tu tente [...] aquela 'culturinha' que tu aprendeu lá, fica contigo" (M2). } \\
\text { "Acho que nem é tanto saber que teu filho tem essa orientação, mas os comentários das pessoas, isso } \\
\text { que te machuca" (M2). } \\
\text { "No nosso tempo, não se ouvia falar nessas coisas, se sentia assim meio que um pouquinho } \\
\text { envergonhado com o pessoal da vizinhança" (P1). } \\
\text { "A minha esposa, [...] ela dizia, 'Será que existe isso aí? Não pode existir isso aí!', daí eu dizia, 'a gente } \\
\text { já ouviu falar, existia'" (P1). }\end{array}$ \\
\hline $\begin{array}{c}\text { Esperança de } \\
\text { mudança }\end{array}$ & $\begin{array}{l}\text { "A gente começou a saber por outras pessoas, [...] mas daí nós pensamos, 'ah deve ser da idade'" (M1). } \\
\text { "Conversei com ele, aconselhei ele, até tentei: 'P. você não está enganado?', sabe as coisas todas que } \\
\text { a gente diz" (M2). }\end{array}$ \\
\hline Alívio do diálogo & $\begin{array}{l}\text { "Uma noite, ele me abraçou e chorava assim de soluçar [...] aí quando ele me contou, eu disse: 'aquela } \\
\text { vez lá era isso?'. Ele disse: 'era, eu não aguentava mais aquilo dentro de mim e tinha medo de te contar, } \\
\text { que tu não aceitasse'. E depois que ele me contou, ele ainda tem umas crises de 'rabujice', mas ele } \\
\text { mudou bastante" (M2). } \\
\text { "Parece que foi uma benção o que aconteceu, porque daí eles ficam mais em casa e tu vê que ficou } \\
\text { mais tranquilo também. Acho que, antes, ele tinha aquela agonia até chegar e falar [...] porque, antes, } \\
\text { tu via ele sempre estressado, nervoso [...] hoje, depois disso, ele tá mais tranquilo" (M5). } \\
\text { "Tu sabendo que pode contar com alguém, do que ter aquilo só pra ti, aquilo me sufocava, aí tu poder } \\
\text { falar com alguém parece que compartilha" (M2). } \\
\text { "Ah, foi uns dias, mas [...] depois comecei mais me abrir, contar até pra colegas e tal [...] e aí eu comecei } \\
\text { a conversar mais sobre isso, fiquei mais tranquila" (M5). }\end{array}$ \\
\hline O tempo & $\begin{array}{l}\text { "O primeiro momento foi assim, meio conturbado [...], mas com o passar do tempo, a gente acaba } \\
\text { aceitando" (M1). } \\
\text { "Hoje é normal pra mim, porque convivo bem com eles aqui em casa [filho e o namorado do filho]. } \\
\text { Procuro fazer o melhor que eu posso pra que fiquem bem, pra que estejam bem" (M2). }\end{array}$ \\
\hline
\end{tabular}




\section{M." INTERACÃO EM 2* PSICOLOGIA}

A reação negativa da família diante da revelação da não heterossexualidade de filhos não é surpreendente, já que existe uma hostilidade social em relação a indivíduos não heterossexuais (LaSala, 2000). As reações dependerão de muitos fatores como: vizinhança, trabalho, relações sociais, comunidade LGBT, geração em que o indivíduo nasceu (D'Augelli, 2005). 0 gênero do sujeito, a composição do conjunto familiar, o número de irmãos, o status socioeconômico, a ordem de nascimento, idade dos pais e idade do filho também são apontados como fatores relevantes (D'Augelli et al., 2005; Ferreira, 2012).

Os membros da família experienciam o conflito entre 0 amor por seu filho/a e seus próprios preconceitos diante da homossexualidade, além do desejo de aceitação social (Goldfried \& Goldfried 2001). Segundo Saltzburg (2007) a dificuldade em relação a revelação da não heterossexualidade de um filho, pode ocorrer pelas mensagens homofóbicas internalizadas pelos pais. Em estudo realizado por Huang, Chen e Ponterotto (2016), explorou-se as experiências de chineses heterossexuais de segunda geração e americanos de Taiwan que têm irmãos biológicos gays. Observou-se uma alteração na dinâmica familiar em torno da revelação da homossexualidade, enquanto alguns pais apoiavam, a maioria reagiu com negação, desaprovação, preocupação e culpa, além de buscar não divulgar a comunidade por considerar que ter um filho gay era vergonhoso.

Ainda, Hammes (2013) afırma que a revelação da orientação não heterossexual pode causar um desconforto na família quanto à perda de reconhecimento e prestígio social. Na pesquisa realizada por Motoyama (2019), entrevistou-se 22 famílias de diferentes locais no Japão a qual buscou examinar como as famílias com um membro LGBT negociam com normas sociais. Observou-se que, mesmo entre os entrevistados que disseram que já haviam aceito o membro, ainda sofriam com conflitos internos do processo, e muitos revelaram o medo de ser alvo de estigma quando outros soubessem que são membros da família de uma pessoa LGBT. Observou-se, também, nesta pesquisa, que fatores como a escolaridade, profissão, religião, status socioeconômico, não foram citados pelos participantes.

Entre os fatores percebidos como associados à aceitação conturbada, percebe-se a esperança dos pais para que o/a filho/a reverta ou mesmo não assuma sua orientação sexual. Os pais passam por uma espécie de negação. Conforme Pachankis e Goldfried (2013), as reações parentais podem seguir um percurso que se inicia na culpa e na negação. A negação propicia uma zona de amortecimento até que os pais possam reencontrar o equilíbrio. Na maioria dos casos a negação é ansiosa e, embora os pais possam ter um certo conhecimento da verdade, se recusam a acreditar na informação, descartando a homossexualidade do/a filho/a como apenas uma fase, ou buscando evidências contrárias (Savin-Williams \& Dubé, 1998).
Ainda, na pesquisa de Jaspal (2019), observou-se a negação como estratégia para lidar com a revelação, mesmo havendo suspeita desde a infância percebe a tendência em negar estar informações, além disso, observou que os pais tinham esperança de que a orientação sexual do filho acabasse mudando e que ele se tornasse heterossexual. Nota-se que em nossa pesquisa a maioria das famílias vivenciou a revelação na adolescência do/a filho/a, período associado às mudanças físicas e psicológicas no indivíduo, possivelmente o que forneça essa esperança de mudança por parte dos pais.

Quanto ao diálogo nas famílias de aceitação conturbada, observa-se que falar pode aliviar o sofrimento tanto dos filhos quanto dos pais. Conforme relato das mães, a revelação trouxe benefícios para os/as filhos/as e para a relação familiar, ao perceberem seus filhos menos estressados e nervosos após a revelação. Também observaram uma melhora nas relações em geral, indicando mais proximidade. Assumir a identidade sexual não heterossexual influencia o modo como se estrutura a vida do sujeito. "Sair do armário" é importante para que o indivíduo LGBT adquira autonomia e participação social, assim como, possibilita do desenvolvimento de sentimentos positivos a respeito de sua orientação sexual, e o enfrentamento ao preconceito (LaSala, 2000; Murasaki \& Galheigo, 2016).

As mães ainda relatam que compartilhar com profissionais e amigos a sua experiência diante da revelação foi um fator que auxiliou no processo e levou a mais aceitação. Como citado pela M2 e M5, quando conseguem abrir a situações para amigos, profissionais a carga de sofrimento diante da revelação diminuiu, podendo compartilhar suas aflições, medos, dúvidas, inseguranças. Segundo Ferreira (2012), o compartilhamento de experiências e a busca de mais informação sobre a orientação sexual são as estratégias mais utilizadas para a aceitação familiar.

Por fım, nas famílias de aceitação conturbada, o tempo demonstrou-se como um fator importante para aceitação. Nesta pesquisa, notou-se que alguns pais passaram a aceitar melhor o filho meses após a revelação, enquanto outros, apesar dos anos decorridos, ainda encontram dificuldades para falar sobre o assunto. Por isso, entendeu-se que, para os participantes deste estudo, o tempo decorrido após a revelação foi fator relevante para a aceitação, mas esse tempo varia para cada família. Na pesquisa realizada por Nascimento (2018), observou que há oscilações na aceitação dos pais diante da revelação da não heterossexualidade de um filho/a ao longo do tempo, mas não é um fator predominante para a aceitação acontecer, pois o processo difere em cada família. Segundo Pachankis e Goldfried (2013), as reações parentais podem seguir um percurso que se inicia na culpa e na negação, podendo atingir a aceitação e integração da orientação sexual do/a filho/a. No entanto, segundo LaSala (2000), a aceitação completa da orientação sexual de um filho/a homossexual pode ser impossível para vários pais. 
$\mathrm{Na}$ Tabela 4, foram apresentados os subtemas relacionados a elementos comuns para pais e mães cuja aceitação foi imediata assim como para aqueles que a vivenciaram de forma conturbada. Constatou-se que esses elementos em comum envolvem: medo do preconceito e violência contra a população LGBT, expectativas quanto à vida futura dos/as fiIhos/as, e o apoio e proteção necessários.

A heteronormatividade é uma normatização da sexualidade, a qual rege a maneira como a sociedade deveria se comportar em relação à sexualidade, sendo a heterossexualidade vista como normal e as outras orientações sexuais como desvios ou patologias (Reis \& Teixeira, 2017). Pachankis e Goldfried (2013) afirmam que o heterocentrismo ou heterossexismo é disseminado pelas ações e suposições em uma sociedade que constata o heterossexual como padrão, desconsiderando as outras orientações sexuais, manifestando-se de forma mais sutil que a homofobia. Todos os participantes relataram ter medo da violência física e verbal que seus filhos/as podem sofrer, além do medo que os próprios filhos/as têm de assumir sua orientação sexual na sociedade. Na presente pesquisa, esse tema se apresentou como o principal fator citado pelos pais, quanto à dificuldade que encontram hoje em relação a orientação não heterossexual dos/as filhos/as. 0 medo do que pode acontecer fora do ambiente familiar, além da dor e sofrimento diante dos comentários e falas preconceituosas de outros indivíduos foi fator preponderante. Os pais citam também a dificuldade de inclusão no mercado de trabalho.

Tabela 4. Elementos Comuns

\begin{tabular}{|c|c|}
\hline Subtema & Exc \\
\hline $\begin{array}{c}\text { Medo do } \\
\text { preconceito e } \\
\text { violência }\end{array}$ & $\begin{array}{l}\text { "Só que tem toda essa preocupação, né, do preconceito, de tudo que tu ouve a respeito [...] na } \\
\text { escola tem preconceito, tem e muito, essa é minha maior preocupação, a violência que tem contra } \\
\text { essas pessoas" (M2). } \\
\text { "Não gosto muito que ele saia, eu tenho muito medo do que pode acontecer, porque tu vê tanta } \\
\text { notícia, tem muito homofóbicos, eles batem, eles agridem, eles ofendem, eles matam" (M3). } \\
\text { "Ele me disse semana passada: 'eu não consigo sair de mão dada, não consigo abraçar na rua, eu } \\
\text { tenho medo do que vão fazer, do que vai vir, não adianta, eu não consigo'" (M3). } \\
\text { "A sociedade ainda é machista, preconceituosa, tanto homem, quanto mulher. Tem grupos que } \\
\text { eles são perigosos, esses dias pegaram uma menina, assim que nem eu [transexual] colocaram } \\
\text { no hospital, estupraram ela, bateram nela, então eu sempre digo pra P. se cuidar" (M4). } \\
\text { "A gente vê, às vezes, no trabalho, tem gente que fala mal dessas pessoas [...] a gente sabe, fica } \\
\text { aguentando, fica segurando, é difícil, complicado. Eu sinto aquela dorzinha no peito, aquela } \\
\text { mágoa" (P1). }\end{array}$ \\
\hline $\begin{array}{c}\text { Expectativas } \\
\text { quanto à vida } \\
\text { futura }\end{array}$ & $\begin{array}{l}\text { "Nós, como pai e mãe, nós queria que eles tivessem família, né? Tivesse uns netinho e tal, mas } \\
\text { enfim, pode ser que um dia eles tenham ainda, um dia formam família mesmo assim, né?" (P1) } \\
\text { "Eu disse pra ele: 'mas meu Deus, nunca vou ter um neto!' [...] Ele me disse: 'Mas existe adoção } \\
\text { pra quê?'" (M2). } \\
\text { "Eu esperava que ele fosse ter uma família, casar, ter filhos, mas ele pode, ele pode ter, como ele } \\
\text { me explicou, 'mãe eu posso constituir uma família'" (M3). }\end{array}$ \\
\hline $\begin{array}{l}\text { Apoio e } \\
\text { proteção }\end{array}$ & $\begin{array}{l}\text { "Eu procurei ficar no lado deles, que eles saibam que podem confiar em mim, que eles, quando } \\
\text { precisam, vou estar aqui sempre, dando apoio" (M2). } \\
\text { "Eu sei da vida dele, da rotina dele, ele me conta o que ele faz, com quem ele vai, aonde ele vai [...]e } \\
\text { se eu não deixasse a porta aberta pra ele, eu sei que isso é o motivo de muitos se matarem" (M3). } \\
\text { "Ela tem o pensamento dela, então as escolhas dela eu vou procurar entender e apoiar, porque } \\
\text { não importa onde ela tiver, com que ela ficar, ela é minha filha!" (M4). }\end{array}$ \\
\hline
\end{tabular}




\section{H. INTERACÃO EM PSICOLOGIA}

O medo dos pais não é fictício diante da realidade vivida em nosso país, em relação às pessoas LGBT, para quem as atitudes dirigidas, geralmente, são de desconforto, desprezo, repulsa e hostilidade (Adams et al., 1996). Pessoas não heterossexuais sofrem desde a não aceitação da orientação sexual no âmbito familiar, passando pela ausência de mercado de trabalho, além da exclusão e o afastamento das comunidades e escolas (Gomes et al., 2013; Sousa, 2016). Um estudo buscou avaliar a discriminação e saúde mental entre jovens gays, lésbicas e bissexuais em Portugal (Freitas et al., 2015). Constatou-se a importância de um ambiente familiar positivo como meio de proteção diante da discriminação social e a necessidade de redução da homofobia e heterossexismo em contextos sociais para promoção do bem-estar dos adolescentes não heterossexuais.

Quanto às expectativas futuras para seus filhos/as, em todos os casos, os participantes desejavam que os mesmos casassem e gerassem filhos. Segundo Soliva e Silva Júnior (2014) com a revelação da orientação não heterossexual, as expectativas quanto a vida futura dos filhos/as são bruscamente alteradas e ameaçadas. Na pesquisa realizada por Huebner e colaboradores (2019), observou que pais relataram maior dificuldade de aceitação da homossexualidade quando os filhos eram mais velhos, sugerindo a dificuldade pelo fato dos pais terem investido mais tempo imaginando um futuro tradicional e heterossexual para o filho, tornando mais difícil se adaptar a uma realidade diferente. Na pesquisa de Jhang (2018), observou-se um roteiro heteronormativo de expectativas históricas, sociais, culturais e políticas profundamente enraizado nos pais de filhos não heterossexuais, onde os pais esperavam pelo ritual do casamento, e que tivessem netos relacionados por sangue, enquanto as expectativas dos filhos/ as eram outras.

Em nossa pesquisa nota-se que as expectativas quanto a vida futura do filho, baseadas na heteronormatividade não se mostraram como fator relevante que dificultasse a aceitação dos pais, contrariando as pesquisas científicas, os pais entrevistados relataram que os filhos podem casar e ter filhos independente de sua orientação sexual. Isso pode ser explicado pelo fato de que, após a revelação, com as explicações que os filhos/as forneceram, esses pais perceberam que a geração de filhos e formação de uma família é possível independentemente da orientação sexual.

Os participantes também relataram a importância de servir como apoio para filhos/as diante do preconceito social. Segundo D' Augelli et al. (2010, todas as evidências apontam para a importância da família e do apoio ao indivíduo não heterossexual. 0 processo de revelação pode iniciar mudanças significativas, levando a mais apoio. Percebe-se que a reação favorável da família, nesses casos, pode desenvolver uma identidade mais positiva. Em estudo realizado por Price e Prozec (2019) para explorar como estudantes universitários gays e lésbicas criaram significado do processo de "coming out" com seus pais, revelou a importância dos pais tranquilizarem seus filhos com amor e apoio incondicionais quanto a sexualidade é revelada, observa ainda em sua pesquisa que indivíduos que percebem o apoio relacionado à sexualidade possuíam maior auto-estima e melhor bem-estar.

Savin-Williams e Dubé (1998) afirmam que a aceitação ocorre quando os pais cumpriram o seu luto e passam a reconhecer o fato de ser pai/mãe de um indivíduo homossexual. 0 filho passa a não ser mais motivo de vergonha, não sendo a homossexualidade um segredo familiar. Grupos de apoio, materiais educacionais e meios de comunicação de massa são considerados fundamentais para levar os pais à aceitação direta (Savin-Williams \& Dubé, 1998). A rede social próxima é muito importante no processo de "sair do armário", manifestada pelo acolhimento de amigos e aceitação da família e/ ou projetos que proporcionem a criação de redes sociais de suporte (Murasaki \& Galheigo, 2016).

\section{CONSIDERAÇÕES FINAIS}

A presente pesquisa buscou explorar reações de mães e pais de pessoas que lhes revelaram sua orientação sexual não heterossexual, um processo conhecido internacionalmente como "coming out". O contexto investigado foi uma cidade do interior da mesorregião noroeste rio-grandense. Os resultados indicaram que o processo de revelação da orientação não heterossexual de um/a filho/a apresentou duas formas de aceitação, a imediata e a conturbada, além de elementos comuns entre as duas formas. As reações parentais mostraram-se não seguir uma ordem específica, mas variaram de acordo com vários fatores, o que evidencia diferenças individuais e situacionais.

A aceitação conturbada dependeu de fatores tais como a culpa pela orientação sexual do/a filho/a, a esperança de que o/a filho/a mudasse sua orientação sexual e a falta de informação. 0 tempo apareceu como variável importante para o resgate dos laços ou para a reflexão sobre as reações do momento inicial da revelação dos/as filhos/as. Por outro lado, a aceitação imediata pareceu ser potencializada pela percepção prévia da homossexualidade do/a filho/a e por informações sobre diversidade sexual e de gênero. Quanto a elementos comuns aos dois tipos de aceitação, os principais foram o medo de que o/a filho/a sofra preconceito e violência, a revisão de expectativas relacionadas ao/à filho/a e a necessidade de apoio e proteção.

Entre as entrevistas, o caso que mais chamou a atenção foi de um pai que é um homem transexual. Embora ele tenha aceitado imediatamente e sem gerar estresse emocional 


\section{H MTERAC̄OOEM ET PSICOLOGIA}

a homossexualidade da filha, por sua vez, a filha ainda não aceita a transexualidade do pai. Isso reforça que os vetores de preconceito ou a característica de estigma relacionado a um marcador social da diferença podem variar em todos os grupos sociais, mesmo os que também sofrem pelo estigma que lhes foi conferido.

Como limitações do estudo, observa-se que, das $11 \mathrm{fa}-$ mílias contatadas 5 se recusaram participar da pesquisa, por não quererem falar sobre o assunto, possivelmente pela dificuldade de aceitação da orientação não heterossexual dos filhos. Já os pais que aceitaram participar da pesquisa, possuíam certo nível de aceitação, o que pode ter impedido a investigação de processos mais conturbados. Nota-se, também, que a maioria dos participantes que aceitaram falar são mães - somente dois pais aceitaram participar da pesquisa, o que pode ter minorado expressões de preconceito que pudessem ser investigadas pelo estudo.

Sugere-se que futuras pesquisas avancem na compreensão do fenômeno por meio de delineamentos de pesquisa mais complexos ou que unam estratégias quantitativas e qualitativas. Nesse sentido, este estudo oferece informações que subsidiam a construção de um instrumento que avalie formas de aceitação e fatores de proteção e risco. Além disso, intervenções que promovam a aceitação de mães e pais quanto à não heterossexualidade de filhos poderiam se basear nos aspectos levantados nesta investigação exploratória.

\section{AGRADECIMENTOS}

Os autores agradecem aos participantes da pesquisa pelas contribuições.

\section{DECLARAÇÃO DA CONTRIBUIÇÃO DOS AUTORES:}

Certificamos que todos os autores participaram suficientemente do trabalho para tornar pública sua responsabilidade pelo conteúdo. A contribuição de cada autor pode ser atribuída como se segue:

M.C contribuiu para administração, análise de dados, conceitualização, investigação, metodologia, redação, tabulação de dados, validação e vizualização; I.B.G contribuiu para análise de dados, conceitualização, metodologia, redação, supervisão, validação e vizualização.

\section{DECLARAÇÃO DE CONFLITOS DE INTERESSE}

Os autores declaram que não há conflitos de interesse no manuscrito submetido.
Monalisa Col Debella e Icaro Bonamigo Gaspodini

\section{DECLARAÇÃO DE FINANCIAMENTO}

A pesquisa relatada no manuscrito não possui financiamento.

\section{REFERÊNCIAS}

Adams, H. E.; Wright, L. W.; Lohr, B. A. (1996). Is homophobia associated with homosexual arousal? Journal of Abnormal Psychology, 105(3), 440-445. https://doi.org/10.1037/ 0021-843X.105.3.440

Afonso, A. C. C. (2015). Rituais familiares e coming out em jovens adultos LGBT: Estudo exploratório [Dissertação de Mestrado, Universidade de Lisboa]. Repositório da Universidade de Lisboa. http://hdl.handle.net/10451/23008.

American Psychological Association - APA. (2011). Definition of terms: Sex, gender, gender identity, sexual orientation. https://www.apa.org/pi/lgbt/resources/sexuality-definitions.pdf.

American Psychological Association - APA. (2012). Guidelines for psychological practice with lesbian, gay, and bisexual clients. The American Psychologist, 67(1), 10-42. https://doi.org/10.1037/a0024659.

American Psychological Association - APA. (2017). IPsyNet statement on LGBTIQ+ concerns. https://doi.org/10.1037/ e506952018-001.

Baiocco, R.; Fontanesi, L.; Santamaria, F.; loverno, S.; Marasco, B.; Baumgartner, E.; Willoughby, B. L. B.; Laghi, F. (2015). Negative parental responses to coming out and family functioning in a sample of lesbian and gay young adults. Journal of GLBT Family Studies, 24(1), 1490-1500. https:// doi.org/10.1007/s10826-014-9954-z.

Boni, V.; Quaresma, S. J. (2005). Aprendendo a entrevistar: Como fazer entrevistas em ciências sociais. Revista Eletrônica dos Pós-graduandos em Sociologia Política da UFSC, 2(1), 68-80. https://doi.org/10.5007/\%25x.

Brandon-Friedman, R. A.; Kim, H. W. (2016). Using social support levels to predict sexual identity development among college students who identify as a sexual minority. Journal of Gay \& Lesbian Social Services, 28(4), 292-316. https:// doi.org/10.1080/10538720.2016.1221784.

Braun, V.; Clarke, V. (2006). Using thematic analysis in psychology. Qualitative Research in Psychology, 3(2), 77-101. https://doi.org/10.1191/1478088706qp063oa.

Cassar, J.; Sultana, M. G. (2016). Sex is a minor thing: Parents of gay sons negotiating the social influences of coming out. Sexuality \& Culture, 20(4), 987-1002. https://doi. org/10.1007/s12119-016-9368-8.

Cazelatto, C. E. C.; Cardin V. S. G. (2016). O discurso de ódio homofóbico no Brasil: Um instrumento limitador da sexualidade humana. Revista Jurídica Cesumar, 16(3), 919-938. https://doi.org/10.17765/2176-9184.2016v16n3p919-938 


\section{H MTERAC̄OOEM ET PSICOLOGIA}

Chrisler, A. J. (2017). Understanding parent reactions to coming out as lesbian, gay, or bisexual: A theoretical framework. Journal of Family Theory \& Review, 9(2), 165-181. https://doi.org/10.1111/jftr.12194

D'Amico, E.; Julien, D.; Tremblay, N.; Chartrand, E. (2015). Gay, lesbian, and bisexual youths coming out to their parents: Parental reactions and youths' outcomes. Journal of GLBT Family Studies, 11(5), 411-437. https://doi.or$\mathrm{g} / 10.1080 / 1550428 \times .2014 .981627$.

D'Augelli, A. R. (2005). Stress and adaptation among families of lesbian, gay and bisexual youth. Journal of GLBT Family Studies, 1(1), 115-135. https://doi.org/10.1300/ J461v01n02_07.

D'Augelli, A. R.; Grossman, A. H.; Starks, M. T. (2005). Parent's awareness of lesbian, gay, and bisexual youths' sexual orientation. Journal of Marriage and Family, 67(2), 474-482. www.jstor.org/stable/3600282.

D'Augelli, A. R.; Grossman, A. H.; Starks, M. T.; Sinclair, K. O. (2010). Factors associated with parents' knowledge of gay, lesbian, and bisexual youths' sexual orientation. Journal of GLBT Family Studies, 6(1), 178-198. https://doi. org/10.1080/15504281003705410.

Ferreira, A. M. F. (2012). A "saída do armário": Um estudo exploratório com mães e pais de lésbicas e gays [Dissertação de mestrado, Universidade do Minho]. RepositóriUM. http:// hdl.handle.net/1822/30461.

Fontanella, B. J.; Luchesi, B.; Saidel, M.; Ricas, J.; Turato, E.; Melo, D. (2011). Amostragem em pesquisas qualitativas: Proposta de procedimentos para constatar saturação teórica. Cadernos de Saúde Pública, 27(2), 389-394. https://doi.org/10.1590/S0102-311X2011000200020.

Frazão, P.; Rosário, R. (2008). 0 coming out de gays e lésbicas e as relações familiares. Análise Psicológica, 26(1), 25-45. https://doi.org/10.14417/ap.475.

Freitas, D. F.; D'Augelli, A. R.; Coimbra, S.; Fontaine, A. M. (2015). Discrimination and mental health among gay, lesbian, and lisexual youths in Portugal: The moderating role of family relationships and optimism. Journal of GLBT Family Studies, 12(1), 68-90. https://doi.org/10.1080/15504 28x.2015.1070704.

Gato, J.; Carneiro, N. S.; Fontaine, A. M. (2011). Contributo para uma revisitação histórica e crítica do preconceito contra as pessoas não heterossexuais. Crítica e Sociedade: Revista de Cultura Política, 1(1), 139-167. www.seer.ufu. br/index.php/criticasociedade/article/view/12542/7715.

Goldfried, M. R.; Goldfried, A. P. (2001). The importance of parental support in the lives of lesbian, gay, and bisexual individuals. Journal of Clinical Psychology, 57(5), 681-693. https://doi.org/10.1002/jclp.1037.
Gomes, A. M.; Reis, A. F.; Kurashige, K. (2013). A violência e o preconceito: As formas da agressão contra a população LGBT em Mato Grosso do Sul. Caderno Espaço Feminino. 26(2), 30-43. www.seer.ufu.br/index.php/neguem/article/ view/24661/13724.

Hammes, B. S. (2013). "Prefiro um filho morto do que um filho viado": Algumas implicações de quando a homofobia é familiar. Revista PerCursos, 14(27), 178-199. https://doi.org /10.5965/1984724614272013178.

Huang, J.; Chen, E. C.; Ponterotto, J. G. (2016). Heterosexual chinese americans' experiences of their lesbian and gay sibling's coming out. Asian American Journal of Psychology, 7(3), 147-158. https://doi.org/10.1037/aap0000051.

Huebner, D. M.; Roche, K. M.; Rith, K. A. (2019). Effects of family demographics and the passage of time on parents: Difficulty with their lesbian, gay, or bisexual youth's sexual orientation. Archives of Sexual Behavior, 48, 1581-1588. https://doi.org/10.1007/s10508-019-1430-9.

Jaspal, R. (2019). Parental reactions to british south asian young men who identify as gay. Journal of GLBT Family Studies, 16(4), 402-417. https://doi.org/10.1080/155042 $8 x .2019 .1684412$.

Jesus, J. G. (2013). O conceito de heterocentrismo: Um conjunto de crenças enviesadas e sua permanência. Psico-USF, 18(3), 363-372. https://doi.org/10.1590/s141382712013000300003.

Jhang, J. (2018). Scaffolding in family relationships: A grounded theory of "coming out" to family. Family Relations, 67(1), 161-175. https://doi.org/10.1111/fare.12302.

LaSala, M. C. (2000). Lesbians, gay men, and their parents: Family therapy for the coming-out crisis. Family Process, 39(1), 67-81. https://doi.org/10.1111/j. 1545-5300.2000.39108.x.

Motoyama, K. (2019). "Coming Out" as a family with an LGB member in Japan: Normalizing strategies and negotiating with social norms. Contemporary Japan, 31(2), 159179. https://doi.org/10.1080/18692729.2019.1657055.

Murasaki, A. C.; Galheigo, S. M. (2016). Juventude, homossexualidade e diversidade: Um estudo sobre o processo de sair do armário usando mapas corporais. Cadernos de Terapia Ocupacional UFSCar, 24(1), 53-68. https://doi. org/10.4322/0104-4931.ctoA00648.

Nascimento, G. C. M. (2018). A perspectiva familiar diante da revelação da orientação homossexual de jovens adultos [Dissertação de Mestrado, Universidade Federal do Triângulo Mineiro]. Biblioteca Digital de Teses e Dissertações da UFTM. http://bdtd.uftm.edu.br/handle/tede/547.

Nascimento, G. C. M.; Scorsolini-Comin F. (2018). A Revelação da homossexualidade na família: revisão integrativa da literatura científica. Temas em Psicologia, 26(3) 1527-1541. http://dx.doi.org/10.9788/TP2018.3-14Pt. 


\section{-4* INTERACÃO EM LF PSICOLOGIA}

Oswald, R. F. (2002). Family and friendship relationships after young women come out as bissexual or lesbian. Journal of Homosexuality, 38(1), 65-83. www.igualdade.gov.pt/images/stories/documentos/documentacao/publicacoes/ Estudo_OrientacaoSexual_IdentidadeGenero.pdf.

Pachankis, J. P.; Goldfried, M. R. (2013). Clinical issues in working with lesbian, gay, and bisexual clients. Psychology of Sexual Orientation and Gender Diversity, 1(S), 45-58. http://dx.doi.org/10.1037/2329-0382.1.S.45.

Price, E. W.; Prosek, E. A. (2019). The lived experiences of GLB college students who feel supported by their parents. Journal of GLBT family studies, 1550-4298. http://dx.doi.org/1 0.1080/1550428X.2019.1593278.

Reis, C. R. da S.; Teixeira, S. A. (2017). Heteronormatividade. Revista Brasileira de Ciências da Vida, 5(3), 1-22.

Robinson, M. A.; Brewster, M. E. (2016). Understanding affiliate stigma faced by heterosexual family and friends of LGB people: A measurement development study. Journal of Family Psychology, 30(3), 353-363. http://dx.doi. org/10.1037/fam0000153.

Saggese, G. S. R. (2009). Quando o armário é aberto: Visibilidade e estratégias de manipulação no coming out de homens homossexuais [Dissertação de Mestrado, Universidade do Estado do Rio de Janeiro]. Biblioteca Biomédica $\mathrm{C}$ do Instituto de Medicina Social. http://www.clam.org.br/bibliotecadigital/uploads/publicacoes/1095_944_saggesespdf.pdf.

Saltzburg, S. (2007). Narrative therapy pathways for re-authoring with parents of adolescents coming-out as lesbian, gay, and bisexual. Contemporary Family Therapy, 29(1), 5769. http://dx.doi.org/10.1007/s10591-007-9035-1.

Savin-Williams, R. C.; Dubé, E. M. (1998). Parental reactions to their child's disclosure of a gay/lesbian identity. National Council on Family Relations Stable, 47(1), 7-13. http://dx. doi.org/10.2307/584845.
Sennott, S.; Smith, T. (2011). Translating the sex and gender continuums in mental health: a Transfeminist approach to client and clinician fears. Journal of Gay \& Lesbian Mental Health, 15(2), 218-234. http://dx.doi.org/10.1080/193597 05.2011 .553779 .

Soliva, T. B.; Silva Júnior, J. B. (2014). Entre revelar e esconder: Pais e filhos em face da descoberta da homossexualidade. Sexualidad, Salud y Sociedad, (17), 124-148. https://doi. org/10.1590/1984-6487.sess.2014.17.08.a.

Sousa, K. J. A. (2016). As diversas manifestações homofóbicas e suas consequências no cotidiano das minorias LGBT. Revista Clóvis Moura de Humanidades, 2(1), 27-44.

Toledo, L. G.; Filho, F. S. T. (2013). Homofobia familiar: Abrindo o armário 'entre quatro paredes'. Arquivos Brasileiros de Psicologia, 65(3) 376-391. http://pepsic.bvsalud.org/scielo. php?script=sci_arttext\&pid=S1809-52672013000300005.

Trevisan, J. S. (2000). Devassos no paraíso: A homossexualidade no Brasil, da colônia à atualidade. Record.

Weeks, J. (2018). O corpo educado pedagogias da sexualidade. Em G. L. Louro (Ed.), O corpo e a sexualidade (pp. 3582). Autêntica.

Zimmerman, L.; Darnell, D. A.; Rhew, I. C.; Lee, C. M.; Kaysen, D. (2015). Resilience in community: A social ecological development model for young adult sexual minority women. American Journal of Community Psychology, 55(1-2), 179190. https://doi.org/10.1007/s10464-015-9702-6.

Submetido em: 16/07/2019 Primeira decisão: 22/04/2020 Aceito em: 02/07/2020 